\title{
Socioeconomic variations in nicotine dependence, self- efficacy, and intention to quit across four countries: findings from the International Tobacco Control (ITC) Four Country Survey
}

\author{
M Siahpush, A McNeill, R Borland, G T Fong
}

Tobacco Control 2006;15(Suppl III):iii71-iii75. doi: 10.1136/tc.2004.008763

See end of article for authors' affiliations .....................

Correspondence to: Mohammad Siahpush, $\mathrm{PhD}$, Centre for Behavioural Research in Cancer, Cancer Control Research Institute, The Cancer Council Victoria, 100 Drummond Street, Carlton 3053, Australia; mohammad.siahpush@ cancervic.org.au

Received 10 May 2004 Accepted 16 November 2004

\begin{abstract}
Objective: To examine the effect of socioeconomic status (SES) on nicotine dependence, self-efficacy, and intention to quit.

Design setting and participants: Data were from the first wave (2002) of the International Tobacco Control (ITC) Four Country Survey (ITC-4), a panel study of over 2000 adult smokers from each of four countries: the United States, Canada, the United Kingdom, and Australia. Data were collected via telephone interviews.

Main outcome measures: Nicotine dependence, intention to quit, and self-efficacy to quit smoking were the main outcome measures used in this study.

Results: Lower levels of education were associated with higher nicotine dependence. The effect of lower income on higher heaviness of smoking index (HIS) scores was significant in Canada, the UK, and Australia. Respondents with low education had 35\% larger odds of low self-efficacy than those with high education. Respondents with low education had $40 \%$ larger odds of having no intention to quit than those with high education. Respondents with low income had $23 \%$ larger odds of having no intention to quit than those with high income. Country was not a moderator of the association of SES with self-efficacy and intention to quit.

Conclusion: To the extent that lower SES smokers are more addicted, they are likely to need more intensive support if they are to be successful in their attempts to quit. Given their lower incomes, this places a special responsibility on government to provide or subsidise such services. This should include access to the widest possible range of effective pharmacotherapies complemented with evidence based counselling and support.
\end{abstract}

S ocioeconomic status (SES) is strongly related to smoking behaviour. ${ }^{1-4}$ The association is so strong that smoking is regarded as a marker for deprivation ${ }^{5}$ and one can identify disadvantaged groups by simply observing their smoking prevalence. ${ }^{6}{ }^{7}$ Not only are social inequalities in smoking prevalence pervasive, but they have been widening in such countries as Australia, the UK, the USA, Spain, Italy, and Denmark in the past few decades. ${ }^{168-13}$ This is to a large extent due to differential cessation rates between socioeconomic groups. ${ }^{14}$ This is also often partly due to the overall prevalence of smoking dropping, resulting in a lower base case for assessing proportional change. Jarvis reported that while in the UK cessation rate doubled among the most affluent groups, there was very little change among the poor between 1973 and 1996. ${ }^{14}$ Similarly, there is evidence for widening social inequalities in cessation in Spain in the period 1987 to $1997 .{ }^{15}$

The mechanism of the link between socioeconomic status and cessation has not been adequately explored. Nicotine dependence, self-efficacy, and intention to quit are strong predictors of the propensity to quit and/or successful cessation. ${ }^{316-22}$ However, the association of SES with these variables has been the subject of few investigations. There are, to our knowledge, only three empirical studies. A British study showed that a composite index of social deprivation (having a manual occupation, not having a car, living in rented housing, being unemployed, and living in crowded conditions) was not associated with a crude measure of desire to quit ("Would you like to give up smoking altogether?") but was associated with dependence (for example, time to first cigarette of the day, perceived difficulty of going for a whole day without smoking, and plasma cotinine, a quantitative measure of smoke intake). ${ }^{.}$Similarly, an association between education and smoke intake (serum thiocyanate) was reported in a study of smokers in the Czech Republic. ${ }^{23}$ Finally, an earlier study documented the relationship between a composite index of social disadvantage and concentrations of saliva and plasma cotinine. ${ }^{24}$ To our knowledge there is no published study that analyses the effect of SES on intention to quit or self-efficacy. However, Jarvis and colleagues reported that, in England, social deprivation is associated with hardcore smoking (defined as having less than a day without cigarettes in the past five years, no attempt to give up smoking in the past 12 months, no desire to give up smoking, and no intention to give up smoking) ${ }^{25}$ It seems that while there may be a social gradient in intention to quit, the evidence for the association of crude measures of motivation to quit and SES is inconclusive.

The aim of this study was to examine the association of SES with nicotine dependence, intention to quit, and selfefficacy to quit in a population sample of adults in the USA, Canada, the UK, and Australia. We also were interested in the extent to which the relationship between SES and those variables differed as a function of country.

Abbreviations: $\mathrm{HSI}$, heaviness of smoking index; ITC-4, International Tobacco Control Four Country Survey; NRT, nicotine replacement therapy; SES, socioeconomic status 


\section{METHODS}

We used data from the International Tobacco Control Four Country Survey (ITC-4), which is a panel study of adult smokers ( $\geqslant 18$ years old) who report having smoked at least 100 cigarettes in their lifetime and who have smoked at least once in the past 30 days in each of four countries: Canada, the United States, the United Kingdom, and Australia. Respondents are participating every year in the two part telephone survey ( 10 minute recruitment survey, followed by a 40 minute main survey usually conducted one week after the recruitment survey). The ITC-4 cohort was constructed from probability sampling methods with telephone numbers selected at random from the population of each country within strata defined by geographic region and community size. The next birthday method was used to select the respondent in households with multiple smokers. Cooperation rates (the ratio of the number of interviews to the sum of the number of interviews and refusals) were high for a survey of this kind: USA $77.0 \%$, Canada $78.5 \%$, UK $78.7 \%$, Australia $78.8 \%$. A full description of the ITC methodology, sample profile, and survey rates, including comparisons with national benchmarks, is available at http:// www.itcproject.org. The data reported in this article are from the Wave 1 survey, which was conducted from October to December 2002. The present analysis is limited to daily smokers, whose characteristics are shown in table 1.

Nicotine dependence was measured using the heaviness of smoking index (HSI), a short form of the Fagerstrom tolerance questionnaire. ${ }^{26-28}$ HSI scores range from 0-6 and are calculated by summing the points for time to first cigarette after waking and number of cigarettes smoked per day. Time to first cigarette is scored: $<5$ mins $=3$ points; 6-30 mins $=2$ points; $31-60$ mins $=1$ point; and $>60$ mins $=0$. Respondents were asked: "On average, how many cigarettes do you smoke each day, including both factory-made and roll-your own cigarettes?" Cigarettes per day is scored: $1-10=0$ points; $11-20=1$ point; 21$30=2$ points; and $>31=3$ points. Higher HSI scores indicate more dependence on nicotine. Self-efficacy was measured with the question: "If you decided to give up smoking completely in the next 6 months, how sure are you that you would succeed? Not at all sure, slightly sure, moderately sure, very sure or extremely sure". Respondents who said "not at all sure" were distinguished from others. Intention to quit was measured with the question: "Are you planning to quit smoking: within the next month? Within the next 6 months? Sometime in the future, beyond
6 months? Or not planning to quit." Those who were not planning to quit were distinguished from others.

Two indicators of SES were available: education and household income. We categorised annual income into "under \$30 000", "\$30 000-\$59 999", and "\$60 000 and over" for the US, Canadian, and Australian samples. For the UK sample, we used the following categories: "£15 000 or under ", "£15 001-£30 000", and " $£ 30001$ and over". These categorisation schemes resulted in a similar distribution across countries and approximated tertile divisions. Education consisted of three categories: less than high school diploma; high school diploma; and some university or a university degree. We did not combine education and income into a single SES index because they represent different dimensions of SES. ${ }^{29}$ Such indices have not been validated and are difficult to interpret. ${ }^{30}$

We used Stata 7 for all statistical analyses. ${ }^{31}$ Ordinary least squares estimation was used for the analysis of nicotine dependence, and logistic regression for the analyses related to intention to quit and self-efficacy. In the self-efficacy analysis we controlled for nicotine dependence. In the intention to quit analysis, we controlled for nicotine dependence and selfefficacy to quit.

\section{RESULTS}

Sample characteristics by country are shown in table 1. The USA and Australia had the highest crude HSI level, followed by Canada, and the UK. The UK had the highest proportion of people with low self-efficacy in quitting and no intention to quit. These proportions were similar for the USA and Australia, and the lowest in Canada.

Table 2 shows the results of OLS regression of HSI on covariates. Because of the significant interaction of country with age, education, and income, a separate equation was estimated for each country. Being male and older was associated with higher levels of HSI. Education had a significant impact on HSI in all equations, such that lower levels of education were associated with higher HSI scores. The effect of lower income on higher HSI scores was significant in Canada, the UK, and Australia, but not in the USA. We note that while there is a significant difference between the adjusted mean of HSI between low and high income in the USA, the variable income (as represented by the set of three dummy variables) did not significantly add to the model $(p=0.10)$. We also note that while the coefficient of "no information" in the UK was significant, there was no significant difference $(p=0.447)$ between HSI

\begin{tabular}{|c|c|c|c|c|}
\hline Variables & $\begin{array}{l}\text { USA } \\
n=1934\end{array}$ & $\begin{array}{l}\text { Canada } \\
n=2000\end{array}$ & $\begin{array}{l}\text { UK } \\
n=2205\end{array}$ & $\begin{array}{l}\text { Australia } \\
n=2066\end{array}$ \\
\hline$\%$ female & 46.5 & 45.9 & 49.3 & 44.8 \\
\hline \multicolumn{5}{|l|}{ Age } \\
\hline $18-24$ & 14.9 & 13.8 & 13.9 & 16.8 \\
\hline $25-39$ & 30.4 & 32.6 & 32.6 & 34.9 \\
\hline $40-54$ & 36.8 & 35.6 & 28.9 & 32.8 \\
\hline $55+$ & 17.9 & 18.0 & 24.6 & 15.4 \\
\hline \multicolumn{5}{|l|}{ Education } \\
\hline Low & 12.6 & 17.2 & 39.8 & 43.9 \\
\hline Medium & 33.5 & 31.8 & 25.1 & 25.3 \\
\hline High & 53.8 & 50.9 & 35.2 & 30.7 \\
\hline \multicolumn{5}{|l|}{ Income } \\
\hline Low & 35.7 & 27.6 & 28.4 & 26.3 \\
\hline Medium & 35.2 & 36.7 & 34.3 & 34.7 \\
\hline High & 21.3 & 27.0 & 27.5 & 33.1 \\
\hline No information & 7.7 & 8.7 & 9.8 & 5.9 \\
\hline Mean HIS & 3.0 & 2.9 & 2.7 & 3.0 \\
\hline$\%$ with low self-efficacy to quit & 27.5 & 19.3 & 39.4 & 28.8 \\
\hline$\%$ with no intention to quit & 25.6 & 18.5 & 35.3 & 25.0 \\
\hline
\end{tabular}


Table 2 Adjusted $\beta$ coefficients and standard errors from the regression of heaviness of smoking index on socioeconomic status indicators and other covariates

\begin{tabular}{|c|c|c|c|c|}
\hline Covariates & USA & Canada & UK & Australia \\
\hline Female & $-0.39(0.07)^{\star *}$ & $-0.30(0.06)^{* *}$ & $-0.38(0.06)^{* *}$ & $-0.30(0.07)^{\star *}$ \\
\hline \multicolumn{5}{|l|}{ Age (years) } \\
\hline $18-24$ & 0 & 0 & 0 & 0 \\
\hline $25-39$ & $0.43(0.11)^{\star *}$ & $0.46(0.10)^{\star *}$ & $0.50(0.12)^{\star *}$ & $0.52(0.10)^{\star *}$ \\
\hline $40-54$ & $0.86(0.11)^{* *}$ & $1.00(0.10)^{* *}$ & $0.78(0.12)^{\star *}$ & $0.91(0.10)^{* *}$ \\
\hline $55+$ & $0.87(0.12)^{\star *}$ & $0.62(0.11)^{* *}$ & $0.70(0.12)^{* *}$ & $1.09(0.12)^{\star *}$ \\
\hline No. of smokers in household & $0.29(0.05)^{* *}$ & $0.10(0.05)^{*}$ & $0.19(0.05)^{\star *}$ & $0.18(0.05)^{* *}$ \\
\hline \multicolumn{5}{|l|}{ Education } \\
\hline Low & $0.46(0.11)^{* *}$ & $0.64(0.09)^{* *}$ & $0.39(0.07)^{\star *}$ & $0.52(0.08)^{\star \star}$ \\
\hline Medium & $0.16(0.08)^{*}$ & $0.44(0.07)^{* *}$ & $0.29(0.08)^{* *}$ & $0.15(0.09)$ \\
\hline High & 0 & 0 & 0 & 0 \\
\hline \multicolumn{5}{|l|}{ Income } \\
\hline Low & $0.22(0.10)^{*}$ & $0.44(0.09)^{* *}$ & $0.25(0.08)^{* *}$ & $0.46(0.09)^{* *}$ \\
\hline Medium & $0.07(0.10)$ & $0.21(0.08)^{*}$ & $0.23(0.08)^{* *}$ & $0.09(0.08)$ \\
\hline High & 0 & 0 & 0 & 0 \\
\hline No information & $0.03(0.15)$ & $0.10(0.13)$ & $0.26(0.12)^{*}$ & $0.16(0.15)$ \\
\hline
\end{tabular}

scores of respondents who provided and those who did not provide information on their income, after controlling for other covariates.

We substituted HSI with time to first cigarette after waking and found that none of our conclusions were altered as the result. We found a similar pattern and strength of relationship between these variables and SES.

Table 3 shows the results of logistic regressions for predicting the probability of low self-efficacy to quit and no intention to quit. There were no significant interactions and only one equation was estimated for each outcome. Being female was associated with higher odds of low self-efficacy and lower odds of having no intention to quit. Being older was associated with higher odds of low self-efficacy and having no intention to quit. Lower education had a significant association with having low self-efficacy and no intention to quit. Low income was associated with having no intention to quit. We note that while the coefficient of "no information" in the intention to quit analysis was significant, there was no significant difference $(p=0.06)$ in the

Table 3 Adjusted odds ratios and $95 \%$ confidence intervals from logistic regression of the probability of having low self-efficacy and having no intention to quit on socioeconomic status indicators and other covariates

\begin{tabular}{|c|c|c|}
\hline Covariates & Low self-efficacy & No intention to quit \\
\hline Female & $1.27(1.15$ to 1.41$)$ & 0.86 (0.77 to 0.96$)$ \\
\hline \multicolumn{3}{|l|}{ Age } \\
\hline $18-24$ & 1 & 1 \\
\hline $25-39$ & $1.38(1.15$ to 1.66$)$ & 1.13 (0.93 to 1.38 ) \\
\hline $40-54$ & $1.74(1.45$ to 2.08$)$ & 1.84 (1.52 to 2.22$)$ \\
\hline $55+$ & 1.95 (1.61 to 2.37 ) & $3.19(2.62$ to 3.89$)$ \\
\hline HIS & $1.33(1.28$ to 1.38$)$ & 1.18 (1.13 to 1.22 ) \\
\hline Low self-efficacy & - & 1.01 (1.00 to 1.02 ) \\
\hline \multicolumn{3}{|l|}{ Country } \\
\hline USA & 1 & 1 \\
\hline Canada & $0.64(0.55$ to 0.74$)$ & 0.65 (0.56 to 0.77$)$ \\
\hline UK & 1.70 (1.47 to 1.96$)$ & 1.51 (1.30 to 1.75$)$ \\
\hline Australia & $0.96(0.83$ to 1.12$)$ & $0.94(0.80$ to 1.10$)$ \\
\hline \multicolumn{3}{|c|}{ 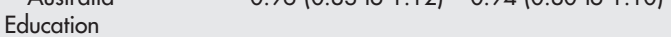 } \\
\hline Low & 1.35 (1.19 to 1.53$)$ & 1.40 (1.23 to 1.60$)$ \\
\hline Medium & $1.02(0.90$ to 1.16$)$ & 1.20 (1.06 to 1.37$)$ \\
\hline High & 1 & 1 \\
\hline \multicolumn{3}{|l|}{ Income } \\
\hline Low & $1.03(0.90$ to 1.19$)$ & 1.23 (1.06 to 1.42$)$ \\
\hline Medium & $0.95(0.83$ to 1.08$)$ & $1.07(0.93$ to 1.23$)$ \\
\hline High & & 1 \\
\hline No information & $0.96(0.78$ to 1.19$)$ & 1.34 (1.08 to 1.66$)$ \\
\hline
\end{tabular}

probability of intention to quit between respondents who provided and those who did not provide information on their income, after controlling for other covariates.

We tested for linear trend of age, education, and income by including them as continuous variables in all regression models. This did not change any of our conclusions about the relationship between these variables and the outcomes.

\section{DISCUSSION}

This study is among the first to demonstrate the strong relationship between SES and behavioural and psychological predictors of cessation across different countries. Our findings revealed that lower SES was associated with higher levels of nicotine dependence, having low self-efficacy to quit, and having no intention to quit, in the USA, Canada, UK, and Australia. While country moderated the effect of SES on nicotine dependence, the conclusion that lower SES groups are more addicted to nicotine holds in all four countries. The effect of SES on self-efficacy was independent of nicotine dependence. The effect of SES on intention to quit was independent of nicotine dependence and self-efficacy to quit. We note the universality of our findings across the four study countries and hypothesise that similar social variations exist in other high income countries.

Higher levels of dependence among lower SES groups may be due to the association of social disadvantage with financial and psychological stress on the one hand, ${ }^{632}$ and the fact that most smokers attribute their smoking to its alleged anxiolytic properties on the other. ${ }^{33}$ In this account, lower SES smokers experience more stress in their daily lives, smoke heavier as a result, and are thus more dependent on nicotine. The association of SES with low self-efficacy and having no intention to quit may be due to social factors. Sorenson and colleagues reported that blue collar workers, compared to other workers, experience less social pressure to quit and less social support for quitting, which in turn are associated with low self-efficacy and having no intention to quit smoking. ${ }^{34}$

The findings suggest that nicotine dependency, intention to quit, and self-efficacy can explain part of the reason cessation rates are lower among lower SES groups. However, the extent to which these variables mediate the impact of SES on cessation should be empirically assessed in future research. We particularly note the complexity of the relationship between SES, intention to quit and cessation. Supplementary analyses of our data suggest that while education was related to the number of previous quit attempts, neither education nor income were related to having made a recent quit attempt (in the past six 
months and one year). This indicates that the effect of intention to quit on cessation might vary by SES, and that the SES differences in intention might not translate into differences in the probability of making quit attempts (at least unsuccessful ones). Although it is not possible to address these issues adequately with cross sectional data, it will be possible to do so with longitudinal data from the ITC-4.

Social variations in dependency, intention to quit, and selfefficacy indicate that population level interventions may be less effective for lower strata, and thus targeted interventions may be essential to reduce the disparity of cessation rates across socioeconomic groups. Targeting will need to focus on the intensity of cessation services offered, but should also be considered in design of motivational campaigns. In particular it may be important to ensure that smokers exposed to motivational advertising in mass media be reminded that there are effective cessation aids available, and be encouraged to use them. However, unless there are adequate resources available, either free or at prices the poor can afford, low SES smokers (in particular) will be being urged to engage in behaviour change without the necessary resources to do so. The resources provided should include both pharmaceutical aids and effective counselling and advice programmes. Similarly, variations in dependency indicate that lower SES groups may require more intensive support for quitting. In particular they would benefit from a wider use of proven pharmacotherapies such as nicotine replacement therapies (NRT) and bupropion, which are shown to significantly increase the success of quit attempts. ${ }^{35}{ }^{36} \mathrm{NRT}$ is most helpful for nicotine dependent smokers, who smoke 15 or more cigarettes per day. ${ }^{37}$ We suggest that it would be beneficial for physicians to recommend NRT to their lower SES patients with high nicotine dependence.

Given that pharmacological aids are usually costly and that compliance and outcomes appear to be better when the smoker does not have to pay for NRT, ${ }^{38}$ we recommend that governments subsidise the cost of pharmacotherapies for people with insufficient means. This recommendation is further supported by supplementary analyses of our data, which revealed that respondents with lower levels of education and income were significantly more likely to agree that "stop-smoking medications are too expensive" (in all four countries), and "stop-smoking medications are too hard to get" (in all countries except Australia). Furthermore, among smokers who intended to quit, those with lower education and income were more likely to report that "free or lower-cost stop-smoking medication" had led them to think about quitting, in all four countries. It is noteworthy that these findings reflect the broader social inequities in access to and availability of health promoting services and health care. $^{39}$

Finally, in light of the research that adding behavioural counselling to NRT increases cessation rates, ${ }^{35}{ }^{36}$ we recommend facilitating and providing behavioural support for lower SES smokers who attempt to quit. In order to rectify the current inequities in quitting (and associated inequities in smoking related morbidity and mortality), it will be necessary to provide lower SES smokers with the kinds of treatment options that are known to be effective and to actively encourage such options.

\section{ACKNOWLEDGEMENTS}

We wish to thank Karen Burns for her research assistance. We are indebted to Melanie Wakefield for her insightful comments. The ITC Project is supported by grants R01 CA 100362 and P50 CAll1236 (Roswell Park Transdisciplinary Tobacco Use Research Center) from the National Cancer Institute of the United States, Robert Wood Johnson Foundation (045734), Canadian Institutes of Health Research (57897), National Health and Medical Research Council of Australia (265903), Cancer Research UK (C312/A3726), Canadian

\section{What this paper adds}

Socioeconomic status (SES) is strongly related to smoking behaviour. Nicotine dependence, self-efficacy to quit, and intention to quit are strong predictors of the propensity to quit and/or successful cessation. However, the association of SES with these variables has been the subject of few investigations

Our findings revealed that lower SES was associated with higher levels of nicotine dependence, having low self-efficacy to quit, and having no intention to quit, in the USA, Canada, UK, and Australia. To the extent that lower SES smokers are more addicted, they are likely to need more intensive support if they are to be successful in their attempts to quit. Given their lower incomes, this places a special responsibility on government to provide or subsidise such services.

Tobacco Control Research Initiative (014578); Centre for Behavioural Research and Program Evaluation, National Cancer Institute of Canada/Canadian Cancer Society. Role of the funding sources: The funding sources had no role in the study design, in the collection, analysis, and interpretation of data, in the writing of the report, and in the decision to submit the paper for publication.

\section{Authors' affiliations}

M Siahpush, R Borland, Cancer Control Research Institute, The Cancer Council Victoria, Australia

A McNeill, Division of Psychology, St George's Hospital Medical School, London, UK

G T Fong, Department of Psychology, University of Waterloo, Waterloo, Ontario, Canada

Competing interest statement: There were no competing interests.

Ethics approval: The study protocol was cleared for ethics by the Institutional Review Boards or Research Ethics Boards in each of the countries: the University of Waterloo (Canada), Roswell Park Cancer Institute (USA), the University of Illinois-Chicago (USA), the University of Strathclyde (UK), and The Cancer Council Victoria (Australia).

\section{REFERENCES}

1 Jarvis MJ, Wardle J. Social patterning of individual health behaviours: the case of cigarette smoking. In: Marmot M, Wilkinson RG, eds. Social determinants of health. Oxford: Oxford University Press, 1999.

2 Siahpush M. Socioeconomic status and tobacco expenditure among Australian households; results from the 1998-99 Household Expenditure Survey. J Epidemiol Community Health 2003:57:798-801.

3 Hymowitz N, Cummings KM, Hyland A, et al. Predictors of smoking cessation in a cohort of adult smokers followed for five years. Tobacco Control 1997;6:s57-62.

4 Shohaimi S, Luben R, Wareham N, et al. Residential area deprivation predicts smoking habit independently of individual educational level and occupational social class. A cross sectional study in the Norfolk cohort of the European investigation into cancer (EPIC-Norfolk). J Epidemiol Community Health 2003;57:270-276

5 Jarvis MJ. A profile of tobacco smoking. Addiction 1994:89:1371-6.

6 Marsh A, McKay S. Poor smokers. London: Policy Studies Institute, 1994

7 Graham $\mathrm{H}$. When life's a drag: women, smoking and disadvantage. London: Department of Health, 1993.

8 Fernandez $E$, Schiaffino, Garcia $M$, et al. Widening social inequalities in smoking cessation. J Epidemiol Community Health 2001;55:729-30.

9 Osler M, Prescott E, Gottschau A, et al. Trends in smoking prevalence in Danish adults, 1964-1994. The influence of gender, age, and education Scand J Soc Med 1998;26:293-8.

10 Osler M, Gerdes LU, Davidsen M, et al. Socioeconomic status and trends in risk factors for cardiovascular diseases in the Danish MONICA population, 1982-1992. J Epidemiol Community Health 2000;54:108-13.

11 White V, Hill D, Siahpush M, et al. How has the prevalence of cigarette smoking changed among Australian adults? Trends in smoking prevalence between 1980 and 2001. Tob Control 2003;12(suppl II):ii67-74.

12 Nelson DE, Emont SL, Brackbill RM, et al. Cigarette smoking prevalence by occupation in the United States. J Occup Med 1994;36:516-25.

13 Faggiano F, Versino E, Lemma P. Decennial trends of social differentials in smoking habits in Italy. Cancer Causes and Control 2001;12:665-71.

14 Jarvis MJ. Patterns and predictors of smoking cessation in the general population. In: Bolliger CT, Fagerstrom KO, eds. The tobacco epidemic. Basel: Karger, 1997:151-64. 
15 Fernandez E, Schiaffino A, Garcia $M$, et al. Widening social inequalities in smoking cessation in Spain, 1987-1997. J Epidemiol Community Health 2001;55:729-30

16 Tillgren $\mathbf{P}$, Halund $B$ J, Lundberg $M$, et al. The sociodemographic pattern of tobacco cessation in the 1980s: results from a panel study of living condition surveys in Sweden. J Epidemiol Community Health 1996;50:625-30.

17 Stronks K, van de Mheen HD, Looman CWN, et al. Cultural, material, and psychosocial correlates of the socioeconomic gradient in smoking behavior among adults. Prev Med 1997:26:754-66.

18 Rose JS, Chassin L, Presson CC, et al. Prospective predictors of quit attempts and smoking cessation in young adults. Health Psychol 1996;15:261-8.

19 Osler M, Prescott E. Psychosocial, behavioural, and health determinants of successful smoking cessation: a longitudinal study of Danish adults. Tobacco Control 1998;7:262-7.

20 Zentner $L$, Borland R. The roles of temptation strength and self-efficacy in predicting smoking cessation attempts. Behaviour Change 1995;12:191-5.

21 Hennrikus DJ, Jeffery RW, Lando HA. The smoking cessation process: longitudinal observations in a working population. Prev Med 1995;24:235-44.

22 Stuart K, Borland R, McMurray N. Self-efficacy, health locus of control, and smoking cessation. Addictive Behaviors 1994;19:1-12.

23 Bobak M, Jarvis MJ, Skodova Z, et al. Smoke intake among smokers is higher in lower socioeconomic groups. Tobacco Control 2000;9:310-12.

24 Cox BD, Huppert F, Whichelow MJ, eds. The health and lifestyle survey: seven years on. Aldershot: Darmouth, 1993.

25 Jarvis MJ, Wardle J, Waller J, et al. Prevalence of hardcore smoking in England, and associated attitudes and beliefs: cross sectional study. BM 2003;326:1061-5.

26 Kozlowski L, Porter CQ, Orleans CT, et al. Predicting smoking cessation with self-reported measures of nicotine dependence: FTQ, FTND, and HSI. Drug and Alcohol Dependence 1994;34:211-16.

27 Heatherton TF, Kozlowski L, Frecker RC, et al. The Fagerstrom test for nicotine dependence: a revision of the Fagerstrom tolerance questionnaire. $\mathrm{Br} J$ Addiction 1991;86:1119-27.
28 Heatherton TF, Kozlowski L, Frecker RC, et al. Measuring the heaviness of smoking: using self-reported time to the first cigarette of the day and number of cigarettes smoked per day. Br J Addiction 1989;84:791-9.

29 Geyer S, Peter R. Income, occupational position, qualification and health inequalities - competing risks? (Comparing indicators of social status). J Epidemiol Community Health 2000;54:299-305.

30 Liberatos $\mathbf{P}$, Link BG, Kelsey JL. The measurement of social class in epidemiology. Epidemiologic Reviews 1988;10:87-121.

31 StataCorp. Stata statistical software: release 7.0, special edition. College Station, Texas: Stata Corporation, 2002.

32 Cohen S, Williamson G. Perceived stress in a probability sample of the United States. In: Spacapan S, Oskamp S, eds. The social psychology of health. Newbury, California: Sage, 1988:31-68.

33 Parrott AC. Does cigarette smoking cause stress? American Psychologist 1999;54:817-20.

34 Sorensen G, Emmons K, Stoddard AM, et al. Do social influences contribute to occupational differences in quitting smoking and attitudes toward quitting? Am J Health Promotion 2002; 16:135-41.

35 Fiore M, Bailey W, Cohen S, et al. Treating tobacco use and dependence. Clinical Practice Guidelines. Rockville, Maryland: US Department of Health and Human Services, Public Health Service, 2000.

36 West RJ, McNeill A, Raw M. Smoking cessation quidelines for health professionals: an update. Thorax 2000;55:987-99.

37 Silagy C, Lancaster T, Stead L, et al. Nicotine replacement therapy for smoking cessation (Cochrane Review). Cochrane Library, Issue 3. Oxford: Update Software, 2001.

38 Hughes JR, Wadland WC, Fenwick JW, et al. Effect of cost on the selfadministration and efficacy of nicotine gum: a preliminary study. Prev Med 1991;20:486-96.

39 Duckett S. Equity in access to health care. In: Eckersley R, Dixon J, Douglas B, eds. The social origins of health and well-being. New York: Cambridge University Press, 2001:149-56. 